(c) 2018 IEEE. Personal use of this material is permitted. Permission from IEEE must be obtained for all other uses, in any current or future media, including reprinting/republishing this material for advertising or promotional purposes, creating new collective works, for resale or redistribution to servers or lists, or reuse of any copyrighted component of this work in other works. 


\section{ESTABLISHING ENTREPRENEURSHIP ECOSYSTEMS BASED ON DIGITAL TECHNOLOGIES: A POLICY ROADMAP APPROACH AT THE CITY LEVEL}

Authors: Cetindamar, D. ${ }^{*}$, Lammers, T. and Sick, N.

School of Systems, Management and Leadership, University of Technology Sydney, Sydney, Australia.

* Corresponding Author

\section{Abstract}

The last decade has witnessed the rise of technology-based entrepreneurs who managed to build companies based on the use of emerging digital technologies. Some of them have become owners of multibillion companies, which have spurred interest of policy makers across the globe to develop new successful unicorns in their own countries. However, the pure availability of digital technologies in a particular country is not enough to establish successful companies. Companies are located in certain regional or urban environments with varying contextual factors. Cities have been a popular unit of analysis for technological development and economic activities due to their high dependency on immediate local environmental factors. Nevertheless, the literature lacks to examine the relationship between technological developments and entrepreneurial activities at city level to identify feasible frameworks to support a digitally competitive entrepreneurial ecosystem. By combining the previous literature on entrepreneurship and digital technologies within a particular urban context, this paper offers a framework to support policy makers plan the future competitiveness of their cities.

Keywords: digital technologies, entrepreneurship ecosystems, city, policy framework

\section{INTRODUCTION}

The recent entrepreneurial ecosystem literature provides several factors affecting the success of an entrepreneurial ecosystem. However, researchers point out the role of local conditions and bottom-up processes and they advise customization of policies rather than copying successful policies applied in other regions such as in Silicon Valley [1,2]. But more importantly, they call policy makers for creating policies for entrepreneurial regional economy rather than for entrepreneurship alone [3]. Agreeing with such a policy approach, this paper emphasizes creating a city-based policy that integrates both entrepreneurship and technology policies to flourish and generate innovations for the overall performance of the ecosystem.

Cities are becoming a rational geographic unit for economic growth for at least two reasons. First, due to rapid urbanization, cities have become a major site of competitiveness [4]. As a United Nations [5] report summarizes, cities account for $70 \%$ of global gross domestic product in 2016. Another reason why cities are an appropriate for policymaking is the recent discussions on smart cities. "Smart Cities" is a concept that encompasses most of the areas where local governments operate: transportation, civic entrepreneurship, democratic transparency, clean energy, and services provision. In other ways, the use of digital technologies as a transformative mechanism to make cities "smart."

Digital technologies such as big data analytics, cloud-based mobility, 3-D printing, and machine learning are attracting attention from entrepreneurs and policy makers for different purposes. On the one hand, the phenomenon of unicorns, start-up companies valued at over $\$ 1$ billion, appeals entrepreneurs to start-up high technology companies. On the other hand, 
policy makers are attracted to host these unicorns at their countries from the perspective of economic value and social welfare. The literature presents a number of studies on digital technologies and entrepreneurial policies carried out independently by disciplines ranging from operations management to entrepreneurship. Thus, this paper proposes an integrative policy approach that brings together entrepreneurs and policy makers in an effort to both develop and commercialize digital technologies at city level.

The paper has five sections. After this short introduction, section two will give a quick overview on entrepreneurship literature related to entrepreneurship ecosystems. Then, section three will present digital technologies and smart cities, followed with a new policy framework that could combine entrepreneurship ecosystem approach in generating city level policies for the utilization of digital technologies. The final section derives a number of avenues for future research

\section{LITERATURE ON ENTREPRENEURIAL ECOSYSTEMS}

Entrepreneurship is the process by which individuals exploit opportunities for innovation [6], while ecosystem refers to the interconnectedness of organizations that are mutually dependent on each other's inputs and outputs. The entrepreneurial ecosystem concept emphasizes that entrepreneurship takes place in a community of interdependent actors. Considering that entrepreneurship is an important source of innovation, productivity growth and employment [7], many countries are searching ways of supporting their local conditions to create an amiable environment for entrepreneurship to flourish in an ever more globalised and competitive world.

Seemingly paradoxical, there is a revival of emphasis on regions and on the importance of geography in economics in the $21^{\text {st }}$ century despite the extent to which globalisation has turned our world into a "global village" [8]. In this context, the entrepreneurial ecosystem approach has commonalities with other established concepts, in particular regional innovation systems [9] and regional innovation management [10]. Similar approaches highlighting the importance of the regional environment as a driver of innovation are industrial districts, industrial clusters and innovative milieus [11]. These concepts are grounded in Marshall's work [12] on industrial districts where economic value results from the interplay of institutions, agglomeration economics and cooperation of firms. The original definition of industrial district is the spatial concentration of firms operating in one particular industry in a town or a few neighbouring small towns where especially small firms cooperate with each other and are embedded in the local community [12].

The attractiveness of a region is a function not only of geographical and socio-economic factors taken in isolation, but also of a complex interplay of external economies characteristic of a prior industrial agglomeration [13]. For example, the sources of agglomeration economies arise from local concentration of customers, which reduce overhead and infrastructure costs; economies of scale in production or distribution, sufficient demand to warrant the provision of specialized infrastructure, deep and diversified pool of workers sufficient to realize a more specialized local division of labour. In the same way, these economies are product of the use of specialized equipment and services; opportunities for bulk purchasing; joint research; organized markets for finished products; reduced cost of negotiating and monitoring contracts; and existence of specialized brokers or specialized machinery producers $[8,12]$. 
Agglomeration economies refers to the unit cost reductions of a firm arising from internal and external economies when it is located together with relatively dense clusters of other firms or specialized resources rather than located elsewhere. These economies fall into one of the following three groups [14]. The first one, internal economies, is related to the idea of economies of scale and caused by the increase of the firm scale of production at one point. The second one, localization economies, is externalities associated with the presence of many other producers in the same industry or sector. The last one, urbanization economies, is externalities associated with the co-presence of firms from diverse industries. In other words, urbanization economies are applicable to all firms in all industries, arising from the enlargement of the total economic size of that location for all industries taken together. Over time, agglomeration economies have become the crucial element for regional and economic policies [14]. Along these lines, Leydesdorff and Deakin [15] pointed out that cities are "key components of innovation systems" because of their dense networks between academia, industry and government. Cities thus provide exceptional circumstances for collaborations across the triple helix as an essential prerequisite for regional development [16].

Cities are not only be the base for the accumulation of ubiquitous assets, economic, physical, as well as networking [17], but they are the implementation arena for many digital technologies. The goal for policy makers could be to find ways to identify the potential industrial clusters in their cities and then to support entrepreneurship ecosystems around them in order to efficiently utilize digital technologies.

\section{LITERATURE ON DIGITAL TECHNOLOGIES AND SMART CITIES}

Digital technologies are general-purpose technologies and have the potential to change all aspects of production, consumption, and government services in our daily life. They will have a massive impact on entrepreneurship ecosystems both by providing new capabilities \& business models and by affecting their environment and its surrounding regulating frameworks (see Figure 1). Current trends in digital technology development include the Internet of Thing (IoT), enhanced data analytics, artificial intelligence (AI) and virtual reality as companies will realize that digital transformation will become an imperative in today's competitive market [17]. Currently, the pace of change provoked by digital technologies is not only accelerating, but also widening. For example, it will not only enable people to increase their capabilities but also increase organizational innovation as well as integrate whole ecosystems and supply chains [18]. These macro trends will bring with them massive regulatory challenges to provide stability on topics such as artificial intelligence and cyber security $[19,20]$. Research goes as far as claiming that advances in digital technology could automate half of today's work by 2055 [21]. 


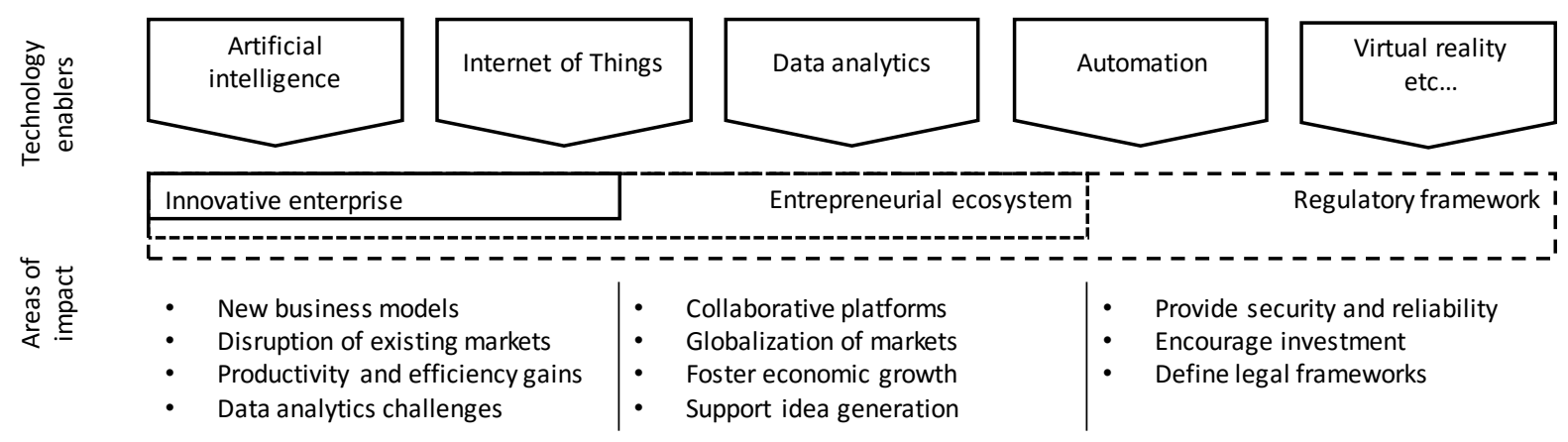

Figure 1: Dimensions of technology impact

Source: Authors.

Originally created in the context of manufacturing companies in Germany, the term Industry 4.0 describes a new trend of automation and data exchange enabled through the revolution through the internet of things, cyber-physical systems and cloud-computing [22]. This technological shift will have a significant impact on global competitive frameworks, as companies change to become integrated networks with high automation levels and real-time data access [23]. Increasing technologically enabled customer demands put further pressure on organisations' competitiveness [24]. The impacts of this shift go beyond manufacturing. It will provide business opportunities and challenges in areas such as logistics, smart services IT infrastructures and workforce management [25]. Thus, any city-based ecosystem policy should consider the ways of integrating digital technologies into ecosystem planning.

For this purpose, the smart city approach provides a valid starting point. The concept of smart cities arose from smart specialisation strategies for regions, where 1) the competitive advantages of the region is identified, 2) R\&D and innovation efforts are targeted in these areas, and 3) based on that, a vision for regional innovation is developed [26]. Smart cities apply these principles on city level, mostly with a focus on ICT as an enabler [27]. Having just emerged with the rise of ICT, there is no coherent definition of a smart city yet, but rather common elements of existing smart city concepts [28]. Key elements are a technology-based networked infrastructure to connect the triple helix partners, business-led/entrepreneurial urban development, a creative class and economic as well as social sustainability [29].

\section{THINKING OF A CITY-BASED FRAMEWORK FOR INTEGRATIVE POLICIES}

The recent entrepreneurial ecosystem literature provides several factors affecting the success of an entrepreneurial ecosystem. However, researchers point out the role of local conditions and bottom-up processes and they advise customization of policies rather than copying successful policies applied in other regions such as in Silicon Valley [1]. But more importantly, they call policy makers for creating policies for entrepreneurial regional economy rather than for entrepreneurship alone [3]. Agreeing with such a policy approach, this paper emphasizes creating a city-based policy that integrates both entrepreneurship and technology policies to flourish and generate innovations for the overall performance of the ecosystem.

Geographical unit for ecosystems could be city, region, nation, or even a group of countries such as NAFTA or European Union. This paper chooses city as a feasible unit of analysis for policy makers due to three major reasons. First, due to the trend of rapid urbanization, there 
are abundant entrepreneurial opportunities. United Nations [5] projects the number of people living in cities to reach to more than six billion people. City population represents not only customer but also workforce, innovators, and entrepreneurs. Second, digital technologies are diffusing rapidly at cities. As discussed in section three, cities have become the major unit of competitiveness [4]. City governments race with each other to build smart cities. Third, city level analysis helps to consider a well-defined unit of location for understanding social, historical, and political fabric, which creates the base for the entrepreneurial ecosystem.

A word of caution, concentrating on city level does not limit understanding the links among different layers of policies. Just on the contrary, it might sharpen the views of the policy makers to see each city and its own networks with other regional layers. In fact, many cities do not compete with local cities alone but rather with global cities in other countries and they try to be a hub for global supply chains by collaborating with some other global cities. By doing so, they become a source of innovation and entrepreneurship at a global level. The more cities are strengthened, the more they contribute to local and national economic growth. However, it gets complicated and policy makers should be equipped to have a rich approach to grasp dynamics of their cities.

\section{Proposal: an integrative city-based policy roadmap for digital technologies and entrepreneurship ecosystems}

The goal is to build an integrative city-based policy for digital technologies and entrepreneurship ecosystems. The roadmap framework might help policy makers to align the capacity of cities in digital technologies with the capacity residing in its entrepreneurship ecosystem $[30,31]$. This could increase utilization of technologies and bring together a number of benefits; three key ones are as follows:

- Local governments develop economic and technology policies for the future economic development. Understanding the impact of digital technologies on city competitiveness requires an understanding of decisions made by numerous stakeholders at city level. Governments, managers and researchers regularly make decisions independent of each other. Bringing them will profoundly influence each city's future development, economic fabric and national competitiveness. Managers are making critical decisions about what technologies to invest: researchers consider what scientific areas to conduct their research; policy makers search support schemes for future and invest in infrastructure and research projects. These decisions call for sound empirical research that takes into account changing contexts, technologies and stakeholders. The proposed roadmap tool contributes to the evidence base to inform decisions in this complex and changing landscape.

- The integrative framework will provide data in two direct ways. First, the roadmap will contribute to integrative policy discussion by bringing the complementary needs of education, entrepreneurship, industrial, innovation and technological policies. Second, the systematic investigation will improve the systemic use of digital technologies for increasing competitiveness of companies and entrepreneurs at city level. The commercialization of science has been a national priority in many countries. The potential changes in industry and technology programs could contribute to competitiveness capacity of cities that will capture of technological opportunities, thus enabling the longterm success for city's economy and welfare. 
- In addition, the roadmap might deliver data in two indirect ways. First, city level data on ecosystem could help to supply input for addressing complementary fields such as education. In particular, the observation of future might be instrumental in planning educational programs to align with future expectations at industrial sectors. This could be helpful in generating inclusive cities by dropping the digital divide in skills. Second, the integrated policy could help efficient use of resources at cities, improving the sustainability of cities. Moreover, adoption of digital technologies by companies will generate many spill over effects such as development of digital capabilities that might be transferrable to other sectors in city environment, contributing to the smartization of cities further.

The proposed framework is not a product or technology roadmap but a policy roadmap. Roadmapping is a powerful technique that has become integral to creating and delivering strategy and innovation in many organisations. A recent work uses it to have multidimensional science and technology planning [32]. The graphical and collaborative nature of roadmaps supports strategic alignment and dialogue between functions in the firm or organization and even between organizations.

Since entrepreneurial ecosystems are embedded within the local context, the roadmapping technique gives a flexibility to policy makers by allowing the alignment of specific needs at all levels, including functional, organisation-wide and even collaboration between organisations. Additionally, roadmapping draws on collaborative strategy making. Decisionmaking is consensus-based and transparent, facilitating key stakeholders to take roadmaps forward and apply according to their need.

This paper proposes to adopt the 4-step roadmapping process based developed by Center for Technology Management at Cambridge University [31, 33, 34, 35]. This paper offers two expansion to the model. First, instead of using original model where firm level analysis comprises technology and market, city-based policy roadmap will investigate policy, technology and market. The process will include Step 1: Policy analysis, Step 2: Industry analysis, Step 3: Technology analysis, and Step 4: Combining parts of maps.

Second, the proposed framework will attempt to include macro-micro analysis for each investigation. While macro-level analysis refers to the assessment of technological and entrepreneurial capacities of a city at the aggregate level, the micro-level covers the assessment of individual stakeholders/organizations (i.e. policy makers, entrepreneurs, firms, innovators).

Figure 1 shows the proposed roadmap process and its outcomes. This multi-dimensional process will bring together entrepreneurship ecosystem actors (industry bodies, suppliers, researchers, innovators, investors, entrepreneurs, and governments). Hence, their policy decisions and technology strategies will contribute to a healthy collaborative endeavour for creating future together. 


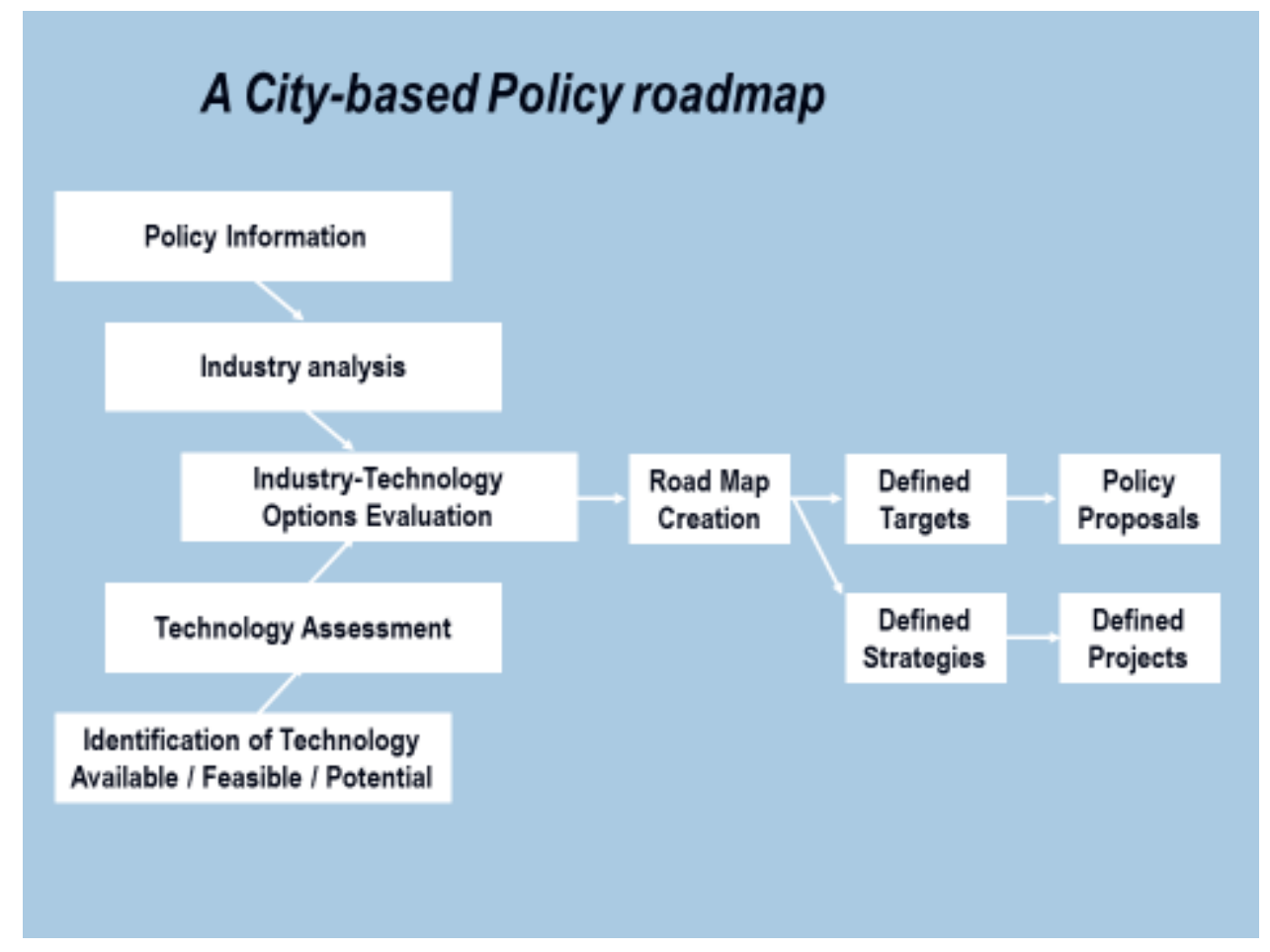

\section{V.SUGGESTIONS FOR FUTURE RESEARCH}

This paper has outlined some of the recent studies regarding entrepreneurship ecosystems and digital technologies. Then, drawing on them, it proposes a roadmapping exercise to develop city based policies in order to develop and commercialize digital technologies at the city level.

This conference paper is a humble effort in developing an integrative approach. It needs to be further developed. Future studies should help to develop policy agenda in a number of ways. They might develop metrics to assess strategic fit between ideal city policies and their realization at city level. They could raise the issue of the alignment of capacities at digital technology and entrepreneurship for a healthy economic growth at cities. They might also conduct empirical studies to collect data and search for ways of streamlining and enriching the proposed framework. In particular, comparative studies might enrich the framework and increase the generalizability of the findings driven from the studies of individual cities.

Future studies might also contribute through innovative methodologies. For example, multiple-methodologies such as bibliometrics could bring valuable information on how best to align digital technologies with entrepreneurial capabilities. There is an ample room for advancing roadmapping tool for policymaking as well. For example, roadmapping exercise could expand to integrate a number of new policy layers by using rich data retrieved from patent analysis and so on.

\section{REFERENCES}


[1] Stam, S. (2015) Entrepreneurial Ecosystems and Regional Policy: A Sympathetic Critique, European Planning Studies, 23 (9): 1759-69.

[2] Isenberg, D. J. (2011) Introducing the entrepreneurship ecosystem: Four defining characteristics, Forbes. Available at

http://www.forbes.com/sites/danisenberg/2011/05/25/introducing-the-entrepreneurshipecosystemfour-defining-characteristics/

[3] Thurik, R., Stam, E., \& Audretsch, D. (2013) The rise of the entrepreneurial economy and the future of dynamic capitalism, Technovation, 33(8-9): 302-10.

[4] Roger, M., Florida, R., Pogue, M., and Mellander, C. (2015) Creativity, clusters and the competitive advantage of cities, Competitiveness Review, 25 (5): 482-96,

[5] UN (2017). World Cities Report 2016. UN: New York.

[6] Schumpeter, J. A. (1934) The Theory of Economic Development (Cambridge, MA: Harvard University Press).

[7] World Economic Forum (2013) Entrepreneurial Ecosystems around the Globe and Company Growth Dynamics (Davos: World Economic Forum).

[8] Henderson, J. V. (1995) Not a Funeral but a Wake: Regional Science in Perspective. International Regional Science Review, 17(3): 333-36.

[9] Cooke, P. (1992) Regional innovation systems: competitive regulation in the new Europe, Geoforum 23(3), 365-382.

[10] Kriz, A., Molloy, C., Kriz, A. and Sonntag, S. (2016). All Australian Regions Are Not Born Equal: Understanding the Regional Innovation Management Sandpit. Technology Innovation Management Review, 6(6): 11-23.

[11] Asheim, B. T., Smith, H. L., \& Oughton, C. (2011). Regional Innovation Systems: Theory, Empirics and Policy. Regional Studies, 45(7): 875-891.

[12] Marshall, A. (1898). Principles of Economics. 4th. Ed. London: Macmillan.

[13] Richardson, H. W. (1995). Economies and Diseconomies of Agglomeration. In ed. Giersch, H. Urban Agglomeration and Economic Growth. Kiel: Springer.

[14] Hoover, E. M. (1975). An Introduction to Regional Economics. 2nd. Ed. NY: Alfred A. Knopf.

[15] Leydesdorff, L. and Deakin, M. (2011). The Triple-Helix Model of Smart Cities: A NeoEvolutionary Perspective. Journal of Urban Technology, 18(2): 53-63.

[16] Katz, B. and Wagner, J. (2014). The Rise of Innovation Districts: A New Geography of Innovation in America. Brookings Institute, Washington, D.C. USA. 
[17] Newman, D. (2017) Top 10 Trends For Digital Transformation In 2018, Forbes CMO Network, https://www.forbes.com/sites/danielnewman/2017/09/26/top-10-trends-for-digitaltransformation-in-2018/\#358985ee293a

[18] Groopman, J., Lieb, R., Owyang, J., \& Szymanski, J. (2017) Three Macrotrends Impacting the Journey to 2030, Kaleido Insights, http://www.kaleidoinsights.com/jeremiah/report.pdf

[19] Dia, H. (2016). Who (or what) is behind the wheel? The regulatory challenges of driverless cars, The Conversation, https://theconversation.com/who-or-what-is-behind-thewheel-the-regulatory-challenges-of-driverless-cars-55434

[20] Hellwig, C. (2017). New perspectives on cyber security: The regulatory challenge, Global Risk Insights, https://globalriskinsights.com/2017/05/new-perspectives-cybersecurity-regulatory-challenge/

[21] Manyika, J., Chui, M., Miremadi, M., Bughin, J., George, K., Willmot, P., Dewhurst, M. (2017) A future that works: Employment, automation and productivity, McKinsey Global Institute

[22] Jasperneite, J. (2012) Was hinter Begriffen wie Industrie 4.0 steckt, Computer Automation, http://www.computer-automation.de/steuerungsebene/steuernregeln/artikel/93559/0/

[23] Brettel, M., Friederichsen, N., Keller, M., Rosenberg, M. (2014) How Virtualization, Decentralization and Network Building Change the Manufacturing Landscape: An Industry 4.0 Perspective, International Journal of Mechanical, Industrial Science and Engineering 8(1): 37-44.

[24] Kumar P. A. (2017) Customer experience trends in digital transformations, CapGemini, https://www.capgemini.com/2017/11/customer-experience-trends-in-digital-transformations/

[25] Schlaepger, R., Koch, M., Merkofer, P. (2014) Industry 4.0 - Challenges and solutions for the digital transformation and use of exponential technologies, Deloitte Report.

[26] OECD (2013). Innovation-driven Growth in Regions: The Role of Smart Specialisation.

[27] Caragliu, A., Bo, C. D. \& Nijkamp, P. (2011) Smart Cities in Europe, Journal of Urban Technology, 18(2): 65-82.

[28] Chourabi, H. et al. (2012). Understanding Smart Cities: An Integrative Framework. Paper presented at the 45th Hawaii International Conference on System Sciences.

[29] Hollands, R.G. (2008) Will the real smart city please stand up? City, 12(3): 303-20.

[30] Kumar, M., Graham, G., Hennelly, P., and Srai, J. (2016). How will smart city production systems transform supply chain design: a product-level investigation. International Journal of Production Research. 54 (23): 7181-92. 
[31] Phaal, R. and Farrukh, C. and Probert, D. (2010). Roadmapping for strategy and innovation - aligning technology and markets in a dynamic world. Institute for Manufacturing, University of Cambridge, Cambridge.

[32] Huang, L., Zhang, Y., Guo, Y., Zhu, D. \& Porter, A.L. (2014). Four dimensional Science and Technology planning: A new approach based on bibliometrics and technology roadmapping, Technological Forecasting and Social Change, 81: 39-48.

[33] Phaal, R. and Farrukh, C. and Probert, D. (2007) Strategic roadmapping: a workshopbased approach for identifying and exploring innovation issues and opportunities.

Engineering Management Journal, 19. pp. 3-12

[34] Phaal, R. and Farrukh, C. and Mitchell, R. and Probert, D. (2003) Starting-up roadmapping fast. IEEE Engineering Management Review, 31. pp. 54-60. ISSN 0360-8581

[35] Kerr, C. and Phaal, R. (2015). A scalable toolkit platform: Configurations for deployment in technology and innovation strategy workshops, R\&D Management Conference. 